\title{
EFFECT OF DUST AEROSOLS IN FORMING THE REGIONAL CLIMATE OF GEORGIA
}

\author{
TEIMURAZ DAVITASHVILI* NATO KUTALADZE ${ }^{\dagger}$ RAMAZ KVATADZE $\ddagger$ AND GEORGE MIKUCHADZE ${ }^{\S}$
}

\begin{abstract}
The effect of the dust on the climate in the Caucasus region, with a specific focus on Georgia, was investigated with a Regional Climate Model RegCM interactively coupled with a dust model. For this purpose we have executed sets of 30 years simulations (1985-2014) with and without dust effects by RegCM4.7 model with 16.7 km resolution over the Caucasus domain and with $50 \mathrm{~km}$ resolution encompassing most of the Sahara, the Middle East, and the Great Caucasus with adjacent regions. Results of calculations have shown that the dust aerosol is an active player in the climate system of Georgia. Mineral dust aerosol influences on temperature and aerosol optical depth spatial and temporally inhomogeneous distribution on the territory of Georgia and generally has been agreed with MODIS satellite data. Results of numerical calculations have shown that dust radiative forcing inclusion has improved simulated summer temperature. The mean annual temperature increased across the whole territory of Georgia in simulations when dust direct effect was considered.
\end{abstract}

Key words: Climate change; Caucasus; Georgia; Dust; RegCM4.7.

AMS subject classifications. $68 \mathrm{M} 14,65 \mathrm{C} 48$

1. Introduction. Dust aerosols in the form of fine particles are scatter and absorb solar and terrestrial radiation and therefore are affect climate [1]. Besides, lifted up from the soils, rocks, plants, volcanic eruptions and anthropogenic pollutants into the atmosphere, dust aerosols can reduce evaporation and as a consequence precipitation processes by reducing the earth surface temperature [2]. Investigations have shown that anthropogenic activities on the average lead to 30 percent of the dust load whereas the storms are the major sources of mineral loading in the environment [3]. The world's biggest desert (Sahara and Sahel in Africa, the Gobi, Kyzylkum, Karakum, Taklamakan in central Asia) storms usually represent the primary sources for the mineral dust aerosols transfer in the atmosphere, its sediment on the earth surface and spreading across the Europe, Asia and Africa continents [1,4]. For instance, desert dust is the principal aerosol component over the Mediterranean basin and they strongly influence the Mediterranean climate [3]. For short or long time periods the dust storms are significantly affecting the earth's atmosphere quality, modifying the clouds microphysics, their optical properties and have a strong influence on both regional and global climate systems. Indeed, dust storms influence the atmospheric radiation budget, the ground surface albedo, the air quality and consequently the human health and the entire biota [5-7]. Numerical modeling of the past, present and future climate processes represents a good means to study the main factors affecting the modern climate change. Several attempts were made to examine the global or regional climate models ability and to clarify the dynamical and physical mechanisms responsible for climate change over the particular regions [3-11]. For instance, for the purpose of assessing the ability of regional climate model to simulate surface solar radiation patterns over Europe the RegCM4.4 model was used [11]. The results of calculations from 2000 to 2009 and their comparisons against the satellite-based observations have shown that the model slightly has overestimated surface solar radiation patterns in Europe.

At present, the simulations of dust cycle in the global and regional climatic models continue to be an important research area. In order to better understand the origin conditions of dust storms and their migration trends, a worldwide effort has been undertaken by numerous researchers to detect the dust aerosols sources into the main and accessory regions, based on the meteorological monitoring networks and satellite observations, in the last decades [12]. As atmospheric aerosols have substantial impacts on the Earth's climate through their direct, semi-direct and indirect effects, the inclusion of aerosol processes (evolution during transportation, deposition, chemical, physical and optical properties) is essential in global and regional climate models. Thus, the study of the dust aerosols life cycle, migration and dust-climate interaction processes by numerical climate models with dust modules currently are widely appreciated in numerous studies [13-17]. Currently climatic

\footnotetext{
* Faculty of Exact and Natural Sciences, I.Vekua Institute of Applied Mathematics of Iv. Javakhishvili Tbilisi State University (teimuraz.davitashvili@tsu.ge)

${ }^{\dagger}$ Hydrometeorological Department/ National Environmental Agency of Georgia

${ }^{\ddagger}$ Georgian Research and Educational Networking Association GRENA

$\S$ Hydrometeorological Department/ National Environmental Agency of Georgia
} 
impacts of aerosols at the global scale are relatively well understood. However, a number of uncertainties still exist in understanding these effects at regional scales [13-15] [16]. It's known that the finest desert dust particles at the near-surface wind threshold conditions are lifted up to high altitudes of troposphere and then are transported thousands of kilometers from the source regions [18]. That is why the effects of the desert dust on climate can be felt not only locally but also in regions far from the sources [14]. Dust aerosol influences and responds to climate change mainly due to its extinction in shortwave radiation, that leads to surface cooling, especially over the arid and semi-arid areas [17].

In order to understand aerosol impacts on climate and environment, a new dust aerosol scheme including emission, transport, gravitational settling and optical property calculations were implemented and tested by the Regional Climate Model (RegCM) [14]. The RegCM/Dust model was run from episodic (few days) to seasonal (climate mode) periods and the model was able to simulate the occurrence of strong dust outbreaks in different regions and to capture the main dust load areas over the Sahel [14]. The coupled chemistry aerosol regional climate model RegCM was used to investigate the dust emission size distribution impact on aerosol budget and its radiative forcing over the Mediterranean region [13]. RegCM-Dust model, with $30 \mathrm{~km}$ horizontal resolution, had been used for estimation of the direct radiative forcing by mineral dust aerosols over the Indian subcontinent throughout 2009 [19]. The results of calculations have shown that the model was able to capture the seasonality of dust emissions, they were reasonably well transported and distributed from the major sources across the IndoGangetic Basin to Himalayan foothills and have 700-850 hPa. The simulations' results of 38 summer monsoon seasons (1969-2006) has shown reduction of average precipitation over the Sahel region executed by the RegCM model with and without dust effects over the African continent. Numerical calculations also have shown that inclusion of dust module into the model has improved the West African monsoon simulation quality [20].

Several attempts were made to examine the RegCM/Dust coupled models' ability for the particular regions [21-23]. For example, the RegCM/Dust coupled model was capable to simulating dust seasonal transport from Sahara towards the South and Central America appropriately [21]. Topography-Modulated dust aerosol distribution and its effects on the atmospheric heat source over the Tibetan Plateau, East Asian summer monsoon onset and prediction of precipitation under different terrain settings in East Asia were successfully studied by RegCM4/Dust coupled model [22]. The results of calculations have shown that the dust greatly increments in the Taklamakan desert (accompanied with the uplift at the northern Tibetan Plateau) and greatly suppresses precipitation in East Asia. Seasonal mean air temperature $\left(C^{\circ}\right)$ and precipitation (mm/day) for the three periods of 2011-2040, 2041-2070 and 2071-2100, with respect to the control period of 1971-2000 above the Central Asia domain was studied by RegCM4.3 model [23]. The results of calculations have shown high rate of warming in the warm season with a decrease in precipitation in almost all parts of the domain and warming trend especially for the northern part of the domain during the cold season [23].

So far, no attempts have been made to study the effect of dust on climate change in the Caucasus region, with particular attention to the territory of Georgia, by regional climate models including dust module. Although, there are several publications on this topic [24-27]. The impact of dust deposition on the Caucasus glacial environment has recently attracted attention of scientists due to the accelerated melting of glaciers in the Caucasus region [24-26]. Generally, dust deposited on glaciers originates from the products of decay of biogenic material, locally-produced mineral dust and long-travelled desert dust [25-26]. For example, a significant desert dust deposition event occurred on Mt. Elbrus (Caucasus Mountains, Russia) on 5th of May 2009, where the deposited dust later appeared as a brown layer in the snow pack which originated in the foothills of the Djebel Akhdar in eastern Libya. The dust sources were activated by the intrusion of cold air from the Mediterranean Sea and Saharan low pressure system and transported to the Caucasus along the eastern Mediterranean coast, Syria and Turkey [27].

It's known that the dust aerosols have an indirect effect on the radiation through effecting cloud microphysics [28]. The most dust aerosols are settled in the atmospheric surface and planetary boundary layers where the atmosphere-surface exchanges energy and water takes place [29]. The dust particles influence microphysical and optical properties of the cloud by scattering and absorbing the short and long wave radiation [30]. The observations have shown that the dust aerosols effect cloud thermodynamic (temperature, relative humidity) and microphysics [31]. The dust aerosols modify cloud properties, the amount, size of cloud droplets and ice crystals [32-34]. Mineral dust aerosols are important components of the Earth's system and have influence on 
the cloud system $[28,35]$ by reflecting solar energy and resulting in surface cooling [36].

The problem of the forthcoming global climate change resulting from natural and growing anthropogenic factors (economical and technological development, overexploitation of land, water, oil and gas resources) gain a particular importance for the territory of Georgia because of its location and compound orography. In Georgia there are 11 types of climate zones from semi-desert to subtropics including mountainous zone of Caucasus with constant snow and glacier. Climate temperature data for the last 100 years have shown climate cooling process in the western and climate warming in the eastern Georgia and also permanence in some micro regions of Georgia. It is necessary to find constantly acting thermal and advective-dynamic sources being responsible for this change. Especially interesting is the impact of increasing concentration of radiation gases, aerosols and dust (dust is one of the main pollutants of the territory of Georgia) on the regional climate, as their accumulation in the lower atmospheric layer plays the role of the scum, which intensifies solar warming of the atmosphere and considerably decreases long-wave flow directed from the Earth to the outer space.

In this study, the RegCM4.7 model coupled with a dust module is configured with a relatively high horizontal resolution $(16,7 \mathrm{~km})$ and used to simulate dust aerosol distribution and its effects on the climate in the Caucasus region. This article examines the role of dust (mineral aerosols) in the regional climate of Georgia by comparing two 30 year simulations executed with and without fully coupled radiatively interactive dust emissions. It was found that RegCM4.7-BATS and its dust model had simulated well the temporal and spatial distributions of mineral aerosols over the Georgia.

2. Model description and data. This study is based on the fourth generation regional climate modeling system RegCM4 [37], where the mineral dust particles' emission, transport and deposition are included [14]. The RegCM4 is a sigma regional climate model with a dynamical core based on the hydrostatic version of the PSU/NCAR Mesoscale MM5 Model [38]. The model has been widely used and tested for the study of regional climatic change and especially for simulations of the effect of dust aerosols in forming the regional climate $[6,14,37]$. The coupled dust module includes dust emission, transport (wet and dry removal), gravitational settling and optical properties' calculations. The dust emission scheme completely depends on the simulated surface wind threshold friction velocity value, boundary layer atmosphere processes and land surface characteristics (surface roughness and soil moisture) which are provided by the surface biosphere-atmosphere transfer scheme BATS. We examine the role of mineral dust effect in forming the regional climate of Georgia by RegCM4/dust model as dust represents the main pollutant for the territory of Georgia [25,39]. During the last decades, there has been a significant improvement in understanding of the dust sources, its transportation, properties and in modeling capabilities [39]. In our study the dust particles are divided into four size bins: fine (0.01-1.0 $\mu \mathrm{m})$, accumulation $(1.0-2.5 \mu \mathrm{m})$, coarse $(2.5-5 \mu \mathrm{m})$, giant $(5.0-20.0 \mu \mathrm{m})$ and we used four steps in dust parameterization [39]. The dust transport, deposition and removal processes have been described in detail in articles [40] [41] and were used in this study.

2.1. Dust Parameters Satellite Measurements. The modeled dust Aerosol Optical Depth (AOD) data have been examined against the Moderate Resolution Imaging Spectroradiometer's (MODIS) data with a $1^{\circ} \times 1^{\circ}$ resolution. There are two MODIS sensors which are observing Earth from polar orbit of NASA's Terra (since February 2000) and Aqua (since June 2002) satellites [42-44]. For this reason, some simulations relating to AOD were executed over 15-year (2000-2014). The retrieved AOD outputs from both Terra and Aqua satellites were used in our study.

The contours of dust load volume concentration were retrieved from the CALIPSO monthly mean gridded $\left(2^{\circ} \times 5^{\circ}\right)$ outputs. The CALIPSO products gave us the aerosol extinction coefficient at $532 \mathrm{~nm}$, column aerosol optical depth and aerosol layer properties in the global grid cells.

2.2. Meteorological data. The results of modeled climate characteristics (among them precipitations) executed by the RegCM4 model are significantly impacted by the boundary conditions (BCs). In our study the BCs for the RegCM4 model domain have been created from ERA-Interim the state-of-the-art global atmospheric reanalysis data which were developed by the European Centre for Medium Range Weather Forecasts [45]. It should be mentioned that observational data have been combined with modeled information from the previous time step in order to construct the global atmospheric conditions. The results of calculations have been validated against Climate Research Unit (CRU) data which present the gridded global climate database of 


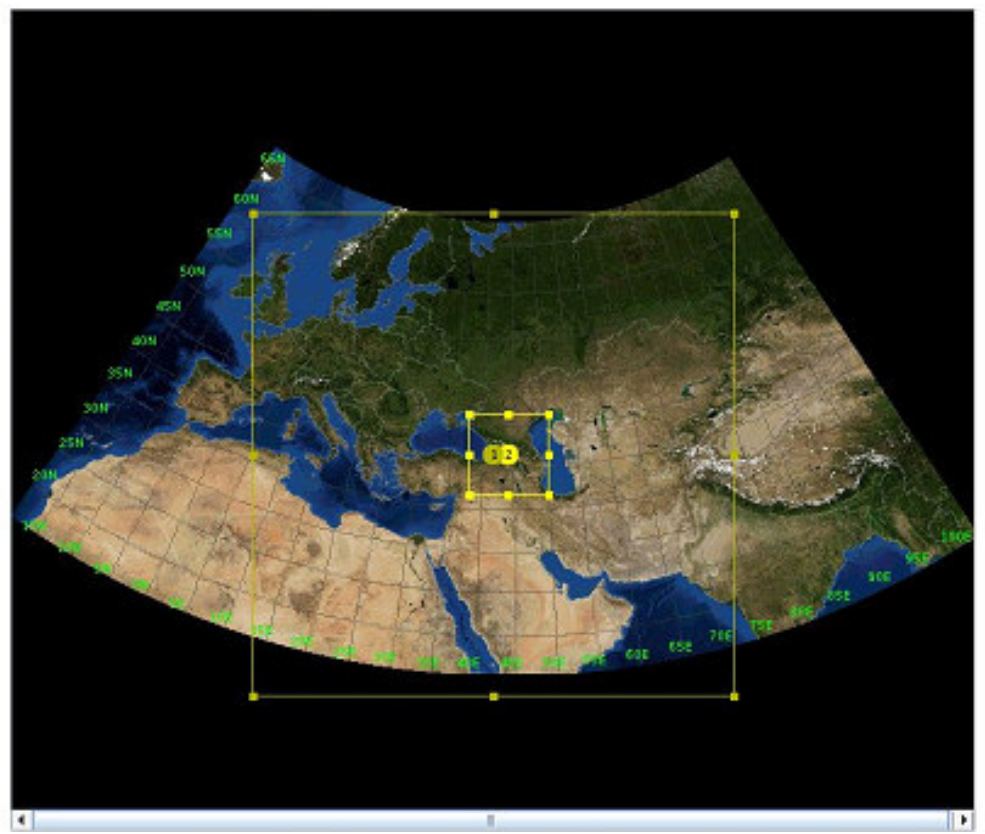

FIG. 3.1. Location of the study area. Coarse and nested domains.

monthly meteorological measurements from ground-based stations [46]. The surface measurements of temperature, among of six meteorological variables datasets, were interpolated into a $0.75 \times 0.75$ grid that have covered the entire land surface of the planet.

3. Experiments design and method. Our investigation was concentrated on modeling the regional climate change of the territory of Georgia based on the latest version of RegCM4.7 using BATS (BiosphereAtmosphere Transfer Scheme) surface code. The study is focused on the impact of locally-produced mineral dust aerosols and long-travelled desert mineral dust on Georgia's regional climate change. As mentioned above, the study over Georgia's territory, similarly to the whole Caucasus region, has a very fragmented character. These studies mostly have focused on strong dust events, when dust particles were observed in Abastumani (Georgia) and in Mt. Elbrus (Russia) [27,47]. The study of regular and long term dust impact on the regional climate has not been carried out for the territory of Georgia yet.

For simulation the period from 1985 to 2014 with boundary conditions from ECMWF ERA-Interim data (with 0.75 degree resolution) was selected. Our model has coarse domain with $50 \mathrm{~km}$ resolution, (it covers all of the regions, which mainly take part in the formation of the atmospheric processes over the Caucasus region, namely: the most of south and east Europe, Ural and Siberian Region, Middle East and Central Asia) and one nested domain (fully covering Caucasus region) with $16.7 \mathrm{~km}$ resolution - see Fig. 3.1.

The impact of dust on the regional climate was evaluated by comparing two numerical experiments in which the first was executed without dust and the second one was simulated through interactive dust inclusion. In order to explore the resolution effect each run was downscaled with nested simulation. For the coarse domains we use time step $100 \mathrm{sec}$. and for the nested ones - $30 \mathrm{sec}$. The coarse domains contain 128 grid points in each of the horizontal directions and 18 vertical levels and the nested domains - 64 and 18 correspondingly.

The same physical schemes were used for Dust and NoDust experiments:

- Holtslag PBL Boundary layer scheme;

- Tiedtke Cumulus convection scheme over the land and the ocean;

- Explicit moisture scheme; In the experiment with Dust only dust tracers - 4 dust bins scheme was activated and aerosol direct effects on radiation and dynamics of atmosphere were considered.

Simulations of the model without chemistry were performed on GRENA's (Georgian Research and Ed- 

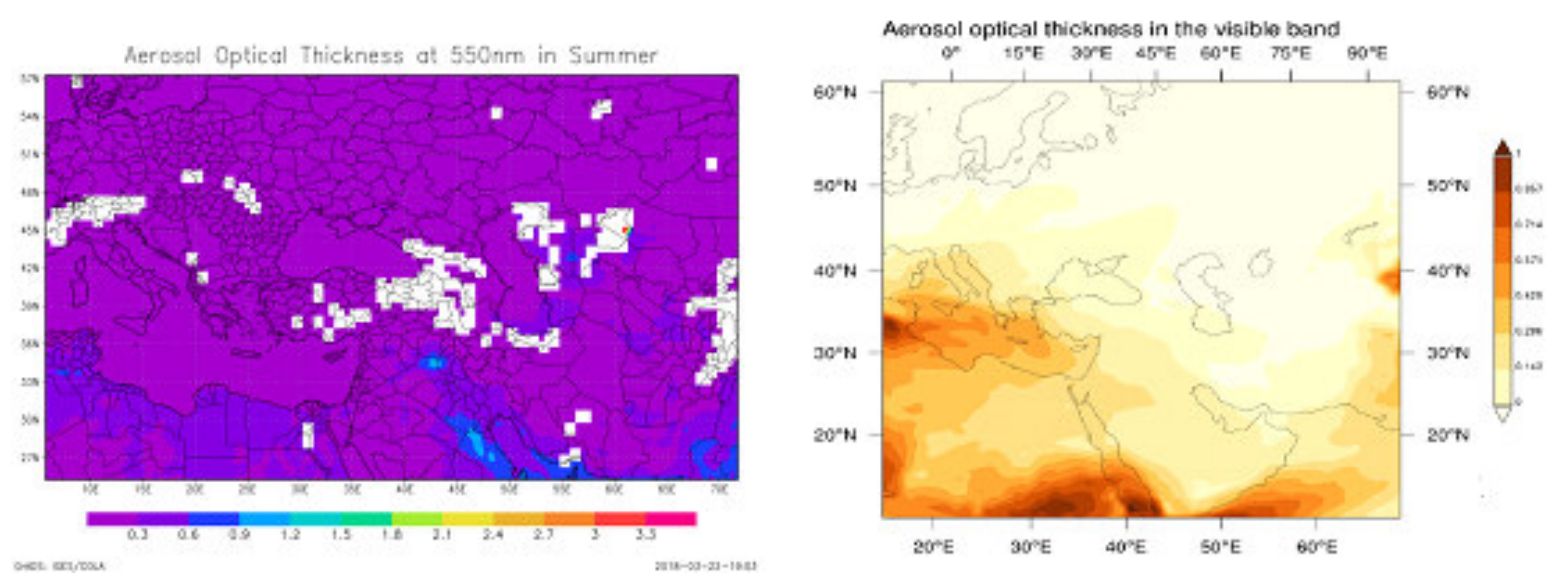

FIG. 4.1. Observed (seawifs) and simulated AOD of summer season for 2000-2014 period.

ucational Networking Association) cluster (one computing node with 15 cores of Intel Xeon CPU E5-2670 @2.60GHz.) It took approximately 135 hours for the coarse domain and 70 hours for the nested one. For the simulations with chemistry more powerful computing resource - high performance computing cluster ARIS of GRNET (Greek Research and Technology Network) was used. The model run was performed on the 60 cores (it corresponds to the 3 nodes) of Intel Xeon CPU E5-2680 v2 @ 2.80GHz. It took approximately 84 hours for the coarse and 60 hours for the nested domains. In order to investigate the usage effect of two different computational resources on model results the same simulations were performed on GRENA and ARIS clusters, the results of calculations were the same.

4. Results and discussions. On the first stage, simulation with dust was validated. As in South Caucasus region we have no ground base stratosphere aerosols observations the only source to examine dust concentration in the air is satellite derived data. The simulated AOD results (aerosol optical depth) were compared to MODIS (MISR, seawifs) data for the four seasons during the period 2000-2014. From the analyses of MODIS data value of the AOD is small in winter as this period of year is characterized by heavy snows that prevent dust accumulation and consequently its values over Caucasus reach only 0.1-0.2 aerosol optical depths observed at characteristic wavelength of $550 \mathrm{~nm}$. The maximum values of the AOD occur in spring and at the beginning of summer season (March-June), when dust is uplifted and transported from the Sahara and Middle East across Mediterranean to the Black Sea's east coast and reaches the Caucasus regions [27]. Indeed, in spring due to activation of dust transportation from Libyan and Egyptian deserts, the circulation process values of AOD increases and it reaches over Caucasus 0.5-0.6 at $550 \mathrm{~nm}$. Also, the observations have shown that the aerosol episodes are frequent during the dry period too, from June to October [42]. In contrast, AOD is minimal in winter. From June to October the subtropical Atlantic high (Azores) prevails over the black sea basin, enhances and causes subsidence. Thus, it results in an extremely stable atmosphere and in absence of rainfall, conditions that favor the aerosol accumulation in the atmosphere. These variations related to synoptic meteorological conditions were investigated previously by authors $[23,27,42]$.

The seasonal distribution pattern of simulated AOD's agrees well with MODIS data. It should be noted that in spring and summer sessions the simulated dust concentrations and corresponding AOD in the dust storm generation regions are overestimated, but for the Caucasus region calculated AOD values are very close to satellite data. For comparison the observed and simulated AOD are presented for summer period on the Fig. 4.1.

To evaluate the impact of dust on the simulated $2 \mathrm{~m}$ temperature all of the 4 runs have been interpolated on nested domain's grid and compared to the 0.50-resolution Climatic Research Unit (CRU) surface temperature (for land only) for annual and seasonal scale. On Fig. 4.2 observed and modeled summer and winter mean 

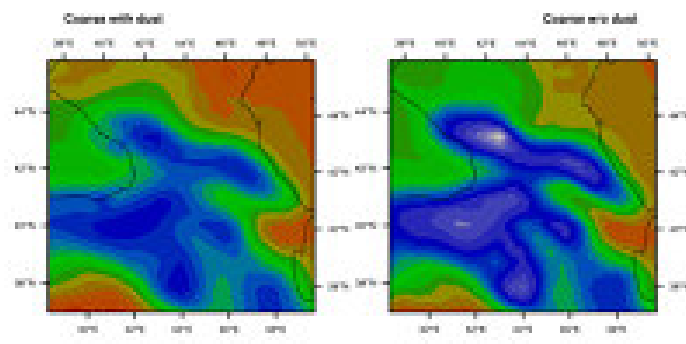$$
\text { - mont }
$$
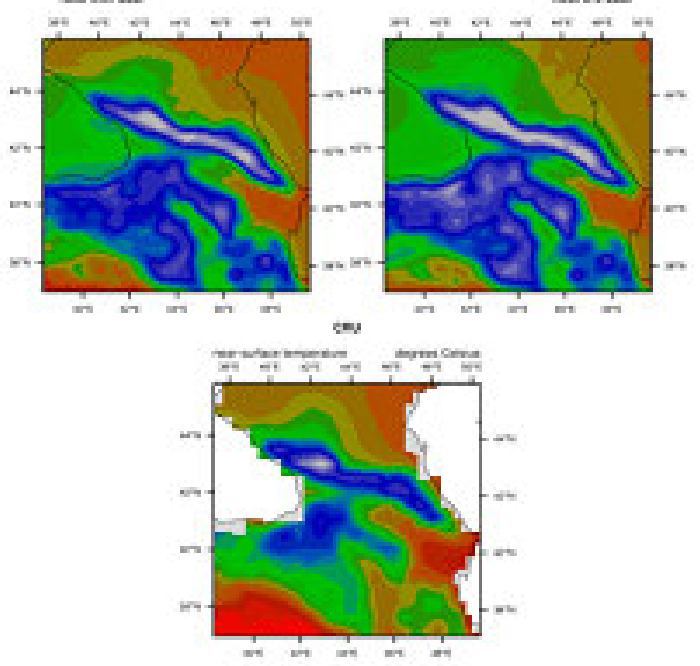

$10 \quad 14 \quad 18 \quad 22 \quad 26 \quad 30$
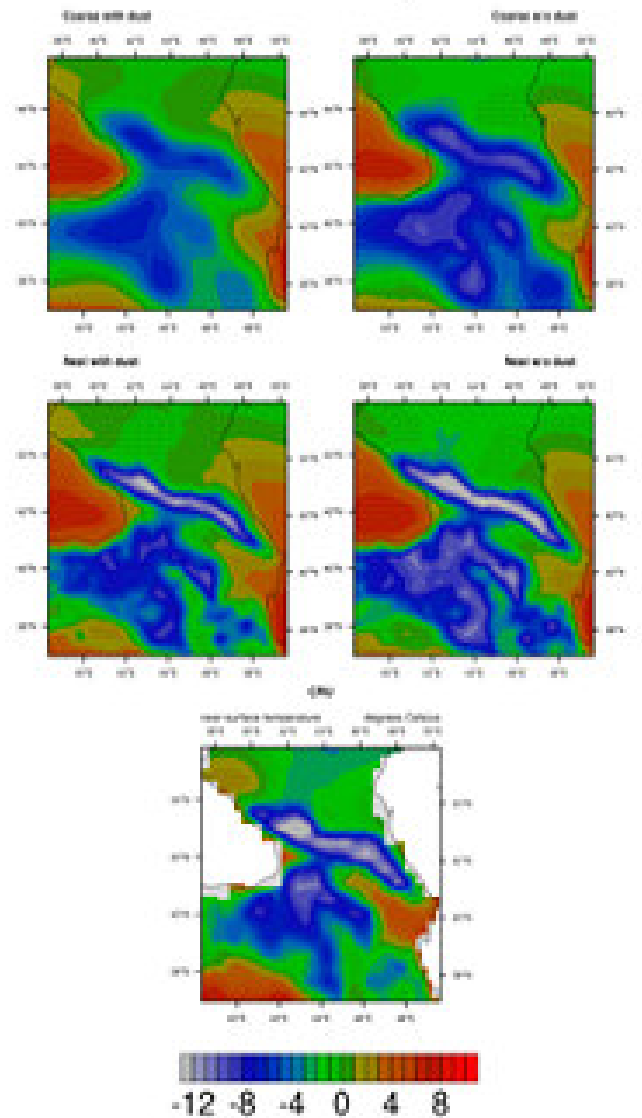

FIG. 4.2. Summer and winter mean surface temperatures observed (CRU) and simulated (with Dust and NoDust on different resolutions).

temperature plots are presented. From these plots difference between experiments with Dust (left on the Fig.) and NoDust is evident, as well as difference between spatial resolutions. It depends on different sub-regions and is in agreement with CRU data.

To examine the simulation performance across the experiments on different sub-regions of the South Caucasus nested domain was divided in 8 sub-regions. These regions mostly cover Georgia's territory but also include some other parts, according to the factors of local climate formation. On Fig. 4.3 location and names of sub-regions are presented, where SCC is Central part of South Caucasus, SWC - Western part of South Caucasus, SEC - Eastern part of South Caucasus, EP - Eastern plane territory, KP - Kolkhety Down land, AJ - South mountainous part of Ajara, JP - Javakhety Plato, CP - Central part of Georgia including Likhi range.

The mean annual, as well as summer and winter temperatures bias, standard deviation and correlation coefficient in comparison with CRU data have been calculated from all of the 4 simulations and mean values across mentioned 8 sub-regions evaluated (Table 4.1).

According to the Table 4.1, annual negative bias appears in all sub-regions for the NoDust simulation, the biggest one is in EP sub-region, bias from Nested NoDust run is even bigger for the most of sub-regions. Dust simulation has evident benefit in reduction of mentioned cold bias, and in the western sub-regions produces warm bias. Nested Dust run also improves performance. Namely for EP sub-region it continues the reduction of negative bias and smoothes bias in other regions produced from the course domain.

On the seasonal scale, Dust experiment improves winter mean temperature simulation for all sub-regions, 


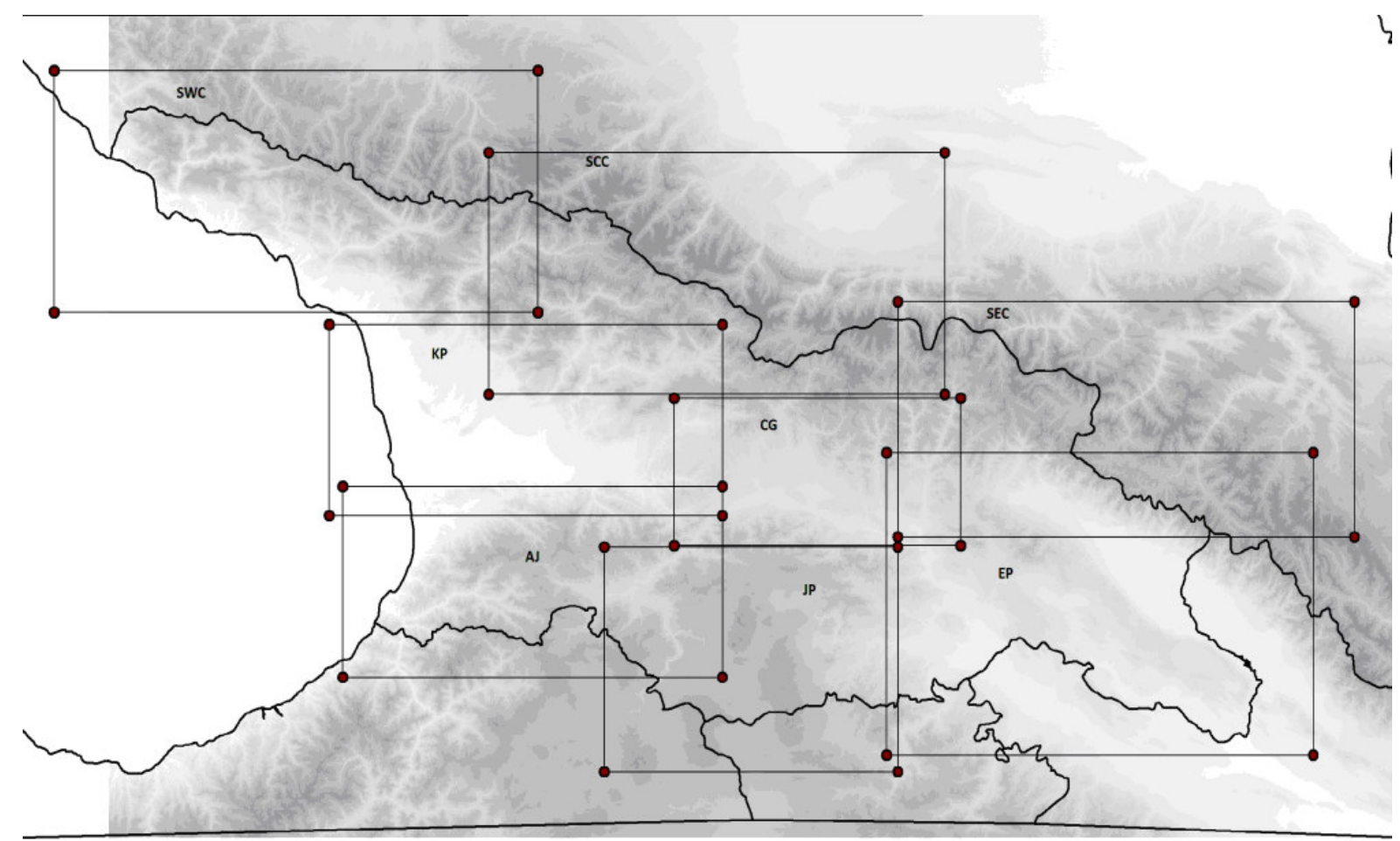

FIG. 4.3. The contours represent the terrain elevation $(m)$. The boxes indicate the 8 sub-regions.

and Nested Dust run performance is better. But summer Dust experiment produces relatively large warm bias for south west sub-regions. The Nested Dust run for summer has better results for some sub-regions than course run. But for others - mostly central regions Nested Dust run simulation increases warm bias. These results are obtained after comparison with $0.5^{\circ}$ resolution observations gridded dataset. Comparing them with finer spatial resolution's observations will be useful to avoid mistakes raised from smoothing local effects.

5. Conclusion. We have investigated the dust's direct effect and its influence on the Georgia climate. This is first attempt to study this problem using RegCM model with dust module taking into account the aerosols radiative forcing in Georgia. In this paper, one climate parameter $2 \mathrm{~m}$ temperature was examined and the difference between Dust and NoDust simulations was found. The mean annual temperature warmed across the whole territory of Georgia in simulations where dust's direct effect was considered. The temperature performance was improved, as it had negative bias in simulation where dust effect wasn't taken into account. The finer resolution temperature results on annual scale have been improved more. On seasonal scale nested run has inhomogeneous results. It differs from sub-region to sub-region and from season to season, and it's especially diverse in summer. This result should be verified by means of rigorous comparison with observations from different sources and resolution. We begin our study from near surface temperature characterization, as it is a well-known and observed variable, but changes in temperature due to the changes in the radiation budget and cloud microphysical processes and thermodynamic state considering the effect of the dust and aerosol. To conclude how our results are relevant for the temperature, it is necessary to examine parameters of the cloud and radiation and continue this study by evaluating these variables.

Acknowledgment. The research in the paper was supported by the EU H2020 project "VRE for regional Interdisciplinary communities in Southeast Europe and the Eastern Mediterranean" VI-SEEM, grant '675121. 
TABLE 4.1

Mean Annual, Temperatures Bias, Standard Deviation and Correlation Coefficient for 8 sub-regions from 4 simulations.

\begin{tabular}{|c|c|c|c|c|c|c|}
\hline & \multicolumn{3}{|c|}{ Dust } & \multicolumn{3}{c|}{ NoDust } \\
\hline & BIAS & STDV & CORREL & BIAS & STDV & CORREL \\
\hline SCC & 1.91 & 1.79 & 0.987 & -0.53 & 1.94 & 0.984 \\
\hline CG & -1.03 & 1.62 & 0.988 & -2.79 & 1.66 & 0.986 \\
\hline SEC & 2.00 & 1.90 & 0.990 & -0.57 & 1.77 & 0.988 \\
\hline EP & -1.99 & 1.49 & 0.990 & -3.15 & 1.47 & 0.989 \\
\hline JP & -0.81 & 1.57 & 0.987 & -2.61 & 1.70 & 0.984 \\
\hline KP & 0.57 & 2.11 & 0.984 & -1.67 & 2.21 & 0.981 \\
\hline AJ & 0.41 & 1.79 & 0.983 & -0.99 & 1.93 & 0.981 \\
\hline SWC & 0.60 & 1.48 & 0.987 & -1.41 & 1.54 & 0.985 \\
\hline
\end{tabular}

\begin{tabular}{|c|c|c|c|c|c|c|}
\hline & \multicolumn{3}{|c|}{ Nested Dust } & \multicolumn{3}{c|}{ Nested NoDust } \\
\hline & BIAS & STDV & CORREL & BIAS & STDV & CORREL \\
\hline SCC & -0.57 & 1.95 & 0.984 & -2.11 & 2.00 & 0.981 \\
\hline CG & -0.81 & 1.72 & 0.987 & -1.99 & 1.71 & 0.985 \\
\hline SEC & -0.44 & 2.08 & 0.987 & -1.72 & 1.89 & 0.987 \\
\hline EP & -1.21 & 1.61 & 0.988 & -2.15 & 1.46 & 0.989 \\
\hline JP & -0.73 & 1.70 & 0.985 & -2.07 & 1.77 & 0.983 \\
\hline KP & -1.03 & 2.16 & 0.983 & -2.43 & 2.10 & 0.982 \\
\hline AJ & -0.41 & 1.93 & 0.980 & -1.90 & 1.93 & 0.979 \\
\hline SWC & -0.52 & 1.57 & 0.984 & -1.83 & 1.64 & 0.982 \\
\hline
\end{tabular}

\section{REFERENCES}

[1] P. Forster, ET AL., Changes in atmospheric constituents and in radiative forcing, in Climate Change 2007, The Physical Science Basis. Contribution of Working Group I to the Fourth Assessment Report of the Intergovernmental Panel on Climate Change, edited by S. Solomon et al., pp. 129- 234, Cambridge Univ. Press, Cambridge, U. K. 
[2] R.L. Miller, I. Tegen and J.P. Perlwitz, Surface radiative forcing by soil dust aerosols and the hydrologic cycle, J. Geophys. Res., 109, D04203, doi:10.1029/2003JD004085, 2004.

[3] F. Barnaba and G. P GobBI, Aerosol seasonal variability over the Mediterranean region and relative impact of maritime, continental and Saharan dust particles over the basin from MODIS data in the year 2001, Atmos. Chem. Phys., 4, 2367-2391, doi:10.5194/acp-4-2367-2004, 2004.

[4] C. Cavazos, M. C. Todd And K. Schepanski, Numerical model simulation of the Saharan dust event of 6-11 March 2006 using the Regional Climate Model version 3 (RegCM3), Journal of Geophysical Research, Vol. 114, pp.1-24, D12109, doi:10.1029/2008JD011078, 2009.

[5] C. ZhaO, ET AL., The spatial distribution of mineral dust and its shortwave radiative forcing over North Africa: modeling sensitivities to dust emissions and aerosol size treatments, Atmos. Chem. Phys. 2010, 10, $8821-8838$. http://dx.doi.org/10.5194/acp-10-8821-2010.

[6] C. ZhaO, ET AL., Radiative impact of mineral dust on monsoon precipitation variability over West Africa, Atmos. Chem. Phys. 11, 1879-1893. http://dx.doi.org/10.5194/acp-11-1879-2011.

[7] J. Huang, ET Al., Dust and black carbon in seasonal snow Across Northern China, Bull. Am. Meteorol. Soc. 92, 175-181. http://dx.doi.org/10.1175/2010BAMS3064.1, 2011.

[8] K.W. Kim, Y.J. Kim and S.J. Оh, S.J., Visibility impairment during Yellow Sand periods in the urban atmosphere of Kwangju, Korea, Atmos. Environ. 35 (30), 5157-5167, 2001.

[9] Y.S. Chen, ET AL., Effects of Asian dust storm events on daily mortality in Taipei? Taiwan, Environ. Res. 95, 151-155, doi: 10.1016/j.envres.2003.08.008, 2004.

[10] M. Aloysius, ET AL., Role of dynamics in the advection of aerosols over the Arabian Sea along the west coast of peninsular India during pre-monsoon season: A case study based on satellite data and regional climate model, J. Earth Syst. Sci. 120, No. 2, 269-279, 2011.

[11] G. AleXANDRI, ET AL., On the ability of RegCM4 regional climate model to simulate surface solar radiation patterns over Europe: an assessment using satellite-based observations, Atmos. Chem. Phys., 15, 13195-13216, 2015, www.atmos-chemphys.net/15/13195/2015/ doi:10.5194/acp-15-13195-2015.

[12] D. G. Kaskaoutis, et AL., Desert Dust Properties, Modelling, and Monitoring, Advances in Meteorology, vol. 2012, Article ID 483632, 2, doi:10.1155/2012/483632, 2012.

[13] P. Nabat, Et AL., Dust emission size distribution impact on aerosol budget and radiative forcing over the Mediterranean region: a regional climate model approach, Atmos. Chem. Phys., 12, 10545-10567, doi:10.5194/acp-12-10545-2012.

[14] A.S. Zakey, F. Solmon, And F. Giorgi, Implementation and testing of a desert dust module in a regional climate model, Atmos. Chem. Phys., 6, 4687-4704, 2006.

[15] Y. P. ShaO, ET AL., Northeast Asian dust storms: real-time numerical prediction and validation, Journal of Geophysical Research, vol. 108, article 4691, 2003.

[16] D. F. Zhang, ET AL., Simulation of dust aerosol and its regional feedbacks over East Asia using a regional climate model, Atmospheric Chemistry and Physics, vol. 9, no. 4, 1095-1110, 2009.

[17] S. Zhaо Eт AL., Simulating direct effects of dust aerosol on arid and semi-arid regions using an aerosol-climate coupled system, International Journal of Climatology, Published online in Wiley Online Library (wileyonlinelibrary.com) DOI: $10.1002 /$ joc.4093, 2014.

[18] N. Mahowald, ET AL., Understanding the 30-year Barbados desert dust record, J. Geophys. Res., 107(D21), doi:10.1029/2002JD002097, 2002.

[19] S. DAS, ET AL., Examining mineral dust transport over the Indian subcontinent using the regional climate model, RegCM4.1, Atmospheric Research 134 (2013) 64-76, 2013.

[20] A. Konare, et AL., A regional climate modeling study of the effect of desert dust on the West African monsoon, Journal of Geophysical Research, Vol. 113, d12206, pp.1-15, doi:10.1029/2007jd009322, 2008.

[21] A. Tsikerdekis et AL., Modeling the trans-Atlantic transportation of Saharan dust, Bulletin of the Geological Society of Greece, vol. L, p. 1052-1061, Proceedings of the 14th International Congress, Thessaloniki, May 2016.

[22] H. Sun, AND X. Liu, Numerical Modeling of Topography-Modulated Dust Aerosol Distribution and Its Influence on the Onset of East Asian Summer Monsoon, Hindawi Publishing Corporation Advances in Meteorology, Vol. 2016, Article ID 6951942, 15 pages, http://dx.doi.org/10.1155/2016/6951942, 2016.

[23] T. Ozturk, Eт AL., Projected changes in temperature and precipitation climatology of Central Asia CORDEX Region 8 by using RegCM4.3.5, Atmospheric Research, 183 296-307, 2017.

[24] M. Shahgedanova, Et Al., Climate Change, Glacier Retreat, and Water Availability in the Caucasus Region, In Book Threats to Global Water Security, Editors: J. Anthony A. Jones, Trahel G. Vardanian, Christina Hakopian ,Publisher Springer Netherlands, 131-140, 2009.

[25] L. Shengelia Et AL., Possibilities of the use of remote sensing technologies for the estimation of modern climate change impact on the Caucasus glaciers, Georgian National Academy of Sciences, Monthly Scientific-Reviewed Magazine, Science and Technologies, Vol. 4-6, 25-30, 2012.

[26] C.R. Stokes, ET AL., Late 20th century changes in glacier extent in the Caucasus Mountains, Russia/Georgia, J. Glaciol., $52,99-109,2006$.

[27] M. Shahgedanova, ET AL., Using the significant dust deposition event on the glaciers of Mt. Elbrus, Caucasus Mountains, Russia on 5 May 2009 to develop a method for dating and "provenancing" of desert dust events recorded in snow pack, Atmos. Chem. Phys., 13, 1797-1808, 2013.

[28] P. KNipPertz AND M. C. TODD. Mineral dust aerosols over the sahara: meteorological controls on emission and transport and implications for modeling, Reviews of Geophysics, 50, 1-28, RG1007 / 2012

[29] Z. LI. Influence of absorbing aerosols on the inference of solar surface radiation budget and cloud absorption. Journal of 
Climate, 11, 5-17, 1998

[30] M.Bangert, Et AL. Saharan dust event impacts on cloud formation and radiation over Western Europe, Atmos. Chem. Phys., 12, 4045-4063, doi:10.5194/acp-12-4045-2012, 2012.

[31] Z. LI, ET AL. Aerosols and Their Impact on Radiation, Clouds, Precipitation, and Severe Weather Events, Environments, Environmental Processes and Systems, Online Publication Date: Sep 2017, DOI:10.1093/acrefore/9780199389414.013.126, 2017

[32] W.-K.TAO, ET AL. Impact of aerosols on convective clouds and precipitation. Reviews of Geophysics, 50, 2012.

[33] N. M. Mahowald, Kiehl, L. M.. Mineral aerosol and cloud interactions. Geophysical Research Letters, 30, 1475-1478, 2003.

[34] G Myhre, et AL. Aerosol-cloud interaction inferred from MODIS satellite data and global aerosol models. Atmospheric Chemistry and Physics, 7, 3081-3101, 2007.

[35] C. Denjean, Et AL. Size distribution and optical properties of mineral dust aerosols transported in the western Mediterranean, Atmos. Chem. Phys., 16, 1081-1104, https://doi.org/10.5194/acp-16-1081-2016, 2016.

[36] S. Twomey. The influence of pollution on the shortwave albedo of clouds. Journal of the Atmospheric Sciences, 34, 1149-1152, 1977.

[37] F. Giongi, ET AL., RegCM4: Model description and preliminary tests over multiple CORDEX domains, Climate Research, 52, 7-29, doi: 10.3354/cr01018, 2012.

[38] G. A. Grell, J. Dudhia And D. R. Stauffer, A description of the fifth-generation Penn State/NCAR Mesoscale Model (MM5), NCAR Tech. Note NCAR/TN- 398+STR, 121 pp, 1994.

[39] H. Sun, Z. PAN AND X. Liu, Numerical simulation of spatialtemporal distribution of dust aerosol and its direct radiative effects on East Asian climate, Journal of Geophysical Research, Atmospheres, vol. 117, no. 13, Article IDD13206, 2012.

[40] Y. GIORgI, ET AL., Regional simulation of anthropogenic sulfur over East Asia 30 and its sensitivity to model parameters, Tellus B, 53, 171-191, doi:10.1034/j.1600-0889.2001.d01-14.x, 2001.

[41] Y. QIAn AND F Giongi, Interactive coupling of regional climate and sulfate aerosol models over East Asia, J. Geophys. Res., 104, 6477-6499, doi:10.1029/98JD02347, 1999.

[42] A. GKIKAS, ET AL., The regime of intense desert dust episodes in the Mediterranean based on contemporary satellite observations and ground measurements, Atmos. Chem. Phys., 13, 12135-12154, doi:10.5194/acp-13- 12135-2013, 2013.

[43] A. Gkikas, et AL., Atmospheric circulation evolution related to desert-dust episodes over the Mediterranean, Q. J. Roy. Meteor. Soc., 141, 1634-1645, doi:10.1002/qj.2466, 2015.

[44] A. Gkikas, ET AL., Characterization of aerosols episodes in the greater Mediterranean Sea area from satellite observations (2000-2007), Atmos. Environ., 128, 286-304, doi:10.1016/j.atmosenv.2015.11.056, 2016

[45] D. P. DeE, ET AL., The ERA-Interim reanalysis: configuration and performance of the data assimilation system, Q. J. Roy. Meteorol. Soc., 137, 553-597, doi:10.1002/qj.828, 2011.

[46] I. HARRIS, ET AL., Updated high-resolution grids of monthly climatic observations- the CRU TS3.10 Dataset, Int. J. Climatol., 34, 623-642, doi:10.1002/joc.3711, 2014.

[47] P. KokKalis ET AL., Ground-, satellite- and simulation-based analysis of a strong dust event over Abastumani, Georgia, during May 2009, International Journal of Remote Sensing, 33:16, 4886-4901, DOI: 10.1080/01431161.2011.644593, 2012.

Edited by: Aneta Karaivanova

Received: Jan 5, 2018

Accepted: Apr 12, 2018 